\title{
Comunicação comunitária e responsabilidade social em clubes de futebol do Brasil e da Europa: muito além do "sócio-torcedor"
}

Community communication and social responsibility in Brazilian and European football clubs: much beyond the "member-supporter"

Comunicación comunitaria y responsabilidad social en clubes de fútbol del Brasil y de Europa: mucho más allá del "socio-hincha"

Ary José Rocco Júnior

- $\quad$ Pós-doutor em Ciências da Comunicação pela Escola de Comunicações e Artes da Universidade de São Paulo (ECA-USP)

- Doutor em Comunicação e Semiótica e mestre em Administração pela Pontifícia Universidade Católica de São Paulo (PUC-SP)

- $\quad$ Professor da Escola de Educação Física e Esporte da Universidade de São Paulo (Eefe-USP)

- Líder e fundador do Grupo de Estudos e Pesquisa em Marketing e Comunicação no Esporte (Gepecom) da Eefe-USP

- E-mail: aryrocco@usp.br

Eduardo de Oliveira Cruz Carlassara

- Mestrando em Gestão e Marketing Esportivo na Eefe-USP

- $\quad$ Especialista em Marketing e Vendas pela Universidade Anhembi Morumbi

- Membro do Grupo de Estudos e Pesquisa em Marketing e Comunicação no Esporte (Gepecom) da Eefe-USP

- $\quad$ Bacharel em Esporte pela Eefe-USP

- E-mail: eduardo.carlassara@usp.br

Pedro Lucas Leite Parolini

- Mestrando em Gestão e Marketing Esportivo na Eefe-USP

- Membro do Grupo de Estudos e Pesquisa em Marketing e Comunicação no Esporte (Gepecom) da Eefe-USP

- Membro do Grupo de Estudos e Pesquisa em Gestão do Esporte (Gepae) da Eefe-USP

- Graduado em Educação Física pela Universidade Federal de Lavras (UFLA)

- E-mail: pedro-parolini@usp.br 


\section{Resumo}

Para os clubes de futebol da Europa, o relacionamento com a comunidade é entendido, ao lado da performance esportiva e do posicionamento de mercado, como um dos vértices de sua atuação estratégica. A comunicação com a comunidade adquire fundamental importância para as agremiações esportivas, contribuindo para sólido relacionamento com grupos de interesse e valorização da marca. 0 objetivo deste artigo é comparar as ações de comunicação com a comunidade dos principais clubes de futebol do Brasil e da Europa. Para isso, analisamos a comunicação nos seus portais oficiais. As organizações brasileiras apresentam entendimento restrito de suas ações com a comunidade, ao contrário das entidades europeias, que investem de forma estratégica nesse tipo de comunicação.

\section{PALAVRAS CHAVE: COMUNICAÇÃO COMUNITÁRIA •RESPONSABILIDADE SOCIAL・CLUBES ESPORTIVOS • FUTEBOL.}

\section{Abstract}

For the football clubs in Europe, the relationship with the community is understood, together with the sports performance and with the market positioning, as one of the vertices of its strategic role. The communication with the community acquires fundamental importance for the sports clubs, contributing to strong relationship with groups of interest and to brand enhancement. The purpose of this article is of comparing the actions for communication with the community of the leading football clubs in Brazil and in Europe. For this we analyze the communication in their official portals. The Brazilian organizations present an understanding that is restricted to their actions with the community, contrary to that of the European entities, which invest strategically in this kind of communication.

\section{KEYWORDS: COMMUNITY COMMUNICATION・SOCIAL RESPONSIBILITY •SPORTS CLUBS・FOOTBALL.}

\section{Resumen}

Para los clubes de fútbol de Europa, la relación con la comunidad se entiende, al lado del rendimiento deportivo y posicionamiento de mercado, como uno de los vértices de su actuación estratégica. La comunicación con la comunidad adquiere una importancia fundamental a las asociaciones deportivas, contribuyendo para un sólido relacionamiento con los grupos de interés y la valorización de la marca. El propósito de este artículo es comparar las acciones de comunicación con la comunidad de los principales clubes de fútbol del Brasil y de Europa. Para esto, analizamos la comunicación a través de los portales oficiales en internet. Las organizaciones brasileras presentan un entendimiento limitado de sus acciones con la comunidad, a diferencia de las entidades europeas, que invierten estratégicamente en este tipo de comunicación. 


\section{ANO 13 • NÚMERO 24 • 1은. 2016 - ORGANICOM COMUNICAÇÃO COMUNITÁRIA E RESPONSABILIDADE SOCIAL EM CLUBES DE FUTEBOL DO BRASIL E DA EUROPA: MUITO ALÉM DO "SÓCIO-TORCEDOR"}

$\mathrm{E}$

m 2015, a entidade The European Club Association (ECA), organização que congrega e representa aproximadamente 220 clubes dos 53' países da Europa, divulgou o ECA club management guide, documento que procurou padronizar as práticas de gestão de clubes de diversos tamanhos e graus de importância do continente. 0 material estabeleceu, como uma de suas premissas principais, que as estratégias de negócios dos clubes europeus apresentam, como objetivos centrais, a performance esportiva, o posicionamento de mercado e o relacionamento com a comunidade. Percebe-se, então, que, para as organizações esportivas europeias, a comunidade ocupa papel central em suas estratégias empresarias.

Por outro lado, no Brasil, os principais clubes de futebol do país investem seus esforços em estratégias mercadológicas e de relacionamento, procurando aumentar sua base de torcedores através dos programas de "sócio-torcedor". As agremiações brasileiras enxergam, nesse tipo de ação, uma das principais fontes para aumentar as suas receitas, adquirindo maior competitividade no mercado do esporte. No entanto, e em direção contrária às suas origens, de natureza social e cultural, não valorizam adequadamente outros agentes da comunidade, importantes para a construção de uma marca sólida e dotada de uma identidade peculiar que caracterize a agremiação.

Nas últimas três décadas, estamos assistindo ao vertiginoso crescimento da chamada Indústria do Esporte. Os negócios relacionados às atividades esportivas têm gerado, ano a ano, um aumento do interesse da população mundial nas atividades relacionadas ao esporte, seja como possibilidade de lazer ou de consumo dos seus produtos, quase sempre ligados ao entretenimento.

Novas estratégias estão surgindo para melhor aproveitamento, por parte das empresas que investem no setor esportivo, de todos os recursos financeiros e potenciais consumidores que esse universo oferece. A gestão do esporte, antes realizada de forma amadora, passou a se profissionalizar e a demandar dos seus atores a aplicação de metodologias ou práticas que levem as organizações esportivas àquilo que é o cerne do papel do gestor do esporte: o equilíbrio entre os resultados econômico, financeiro e esportivo das entidades que administram.

A partir da década de 1990, com o aprofundamento da globalização, o desenvolvimento tecnológico e a unificação dos mercados, os principais clubes de futebol do planeta transformaram-se em verdadeiras empresas multinacionais. Suas marcas passaram a ser trabalhadas globalmente e as receitas financeiras oriundas dos sistemas midiáticos cresceram de forma exponencial. Todos esses fatores, aliados ao desenvolvimento da tecnologia, passaram a demandar, por parte dessas agremiações, um sistema de gestão extremamente profissional.

Com isso, a cultura das diferentes nacionalidades, que até então norteava a prática do esporte, passou, mesmo que de forma inconsciente, a ser moldada dentro de uma estrutura empresarial. Os principais clubes do mundo, formados por atletas de diversas nacionalidades, começaram a perceber que o desenvolvimento de uma cultura própria, com a criação de uma identidade calcada em valores próprios das agremiações, em geral, resultava em excelentes resultados nas competições esportivas. A comunicação com a comunidade e as ações de responsabilidade social, à medida que trabalham os valores institucionais das agremiações esportivas, assumem importante papel na construção da identidade da agremiação e, consequentemente, de seu valor de mercado enquanto marca.

O objetivo deste artigo é comparar, através da análise das informações contidas em seus portais de internet, a comunicação com a comunidade realizada pelas principais equipes da Europa e do Brasil. Para isso, foram escolhidas, por valor de marca, as oito principais equipes do Velho Continente e o mesmo número de agremiações brasileiras. 
A partir da construção comparativa e cruzada dos casos estudados, de forma qualitativa, foi possível levantar a existência, ou não, de uma proposta de filosofia de comunicação com a comunidade e de responsabilidade social para cada uma das agremiações europeias e brasileiras pesquisadas.

Com isso, e através deste estudo, levantamos e avaliamos o atual estágio da comunicação com a comunidade realizada pelos clubes de futebol do Brasil, em comparação ao que ocorre com seus pares na Europa. Entendemos que, dessa forma, estamos oferecendo uma contribuição concreta para a melhoria da gestão de clubes e entidades esportivas em todo o país.

\section{OS CLUBES DE FUTEBOL E A COMUNICAÇÃO COMUNITÁRIA}

0 desenvolvimento correto e adequado do gerenciamento das comunicações interna e externa, dentro do conceito de comunicação integrada, desenvolvido por Margarida M. Krohling Kunsch (2003) (Figura 1), traz excelentes reflexos nos resultados econômico e financeiro das organizações empresariais.

Figura 1-Comunicação organizacional integrada.

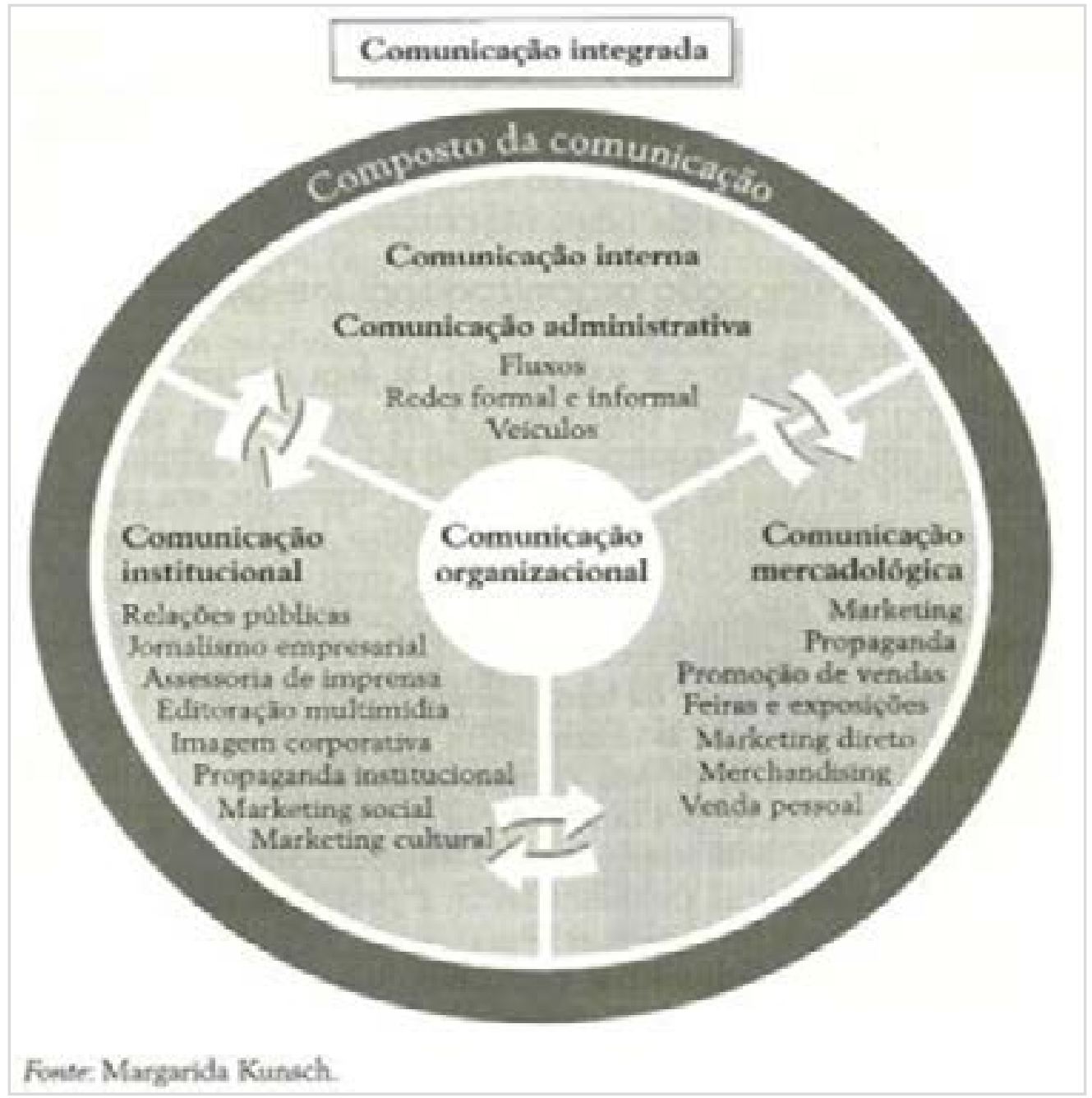

Fonte: Kunsch, 2003, p. 151

A gestão estratégica da comunicação integrada em organizações empresariais é fundamental para o processo de identificação das empresas com seus diversos grupos de interesses. Esse processo de identificação será, ou não, mais bem construído a partir da estruturação, por parte das organizações empresariais, de uma adequada filosofia de comunicação integrada que transmita, em um só sentido, as diversas facetas das relações que elas mantêm com seus mais variados stakeholders. 
No mesmo sentido do conceito de comunicação integrada proposto por Kunsch (2003; 2006), Paul Pedersen, Kimberly Miloch e Pamela Laucella (2007, p. 85), no livro Strategic sport communication, apresentam um interessante modelo estratégico para a comunicação no esporte que integra todas as vertentes da comunicação propostas pela pesquisadora brasileira (Figura 2).

Figura 2 - Modelo de comunicação esportiva estratégica.

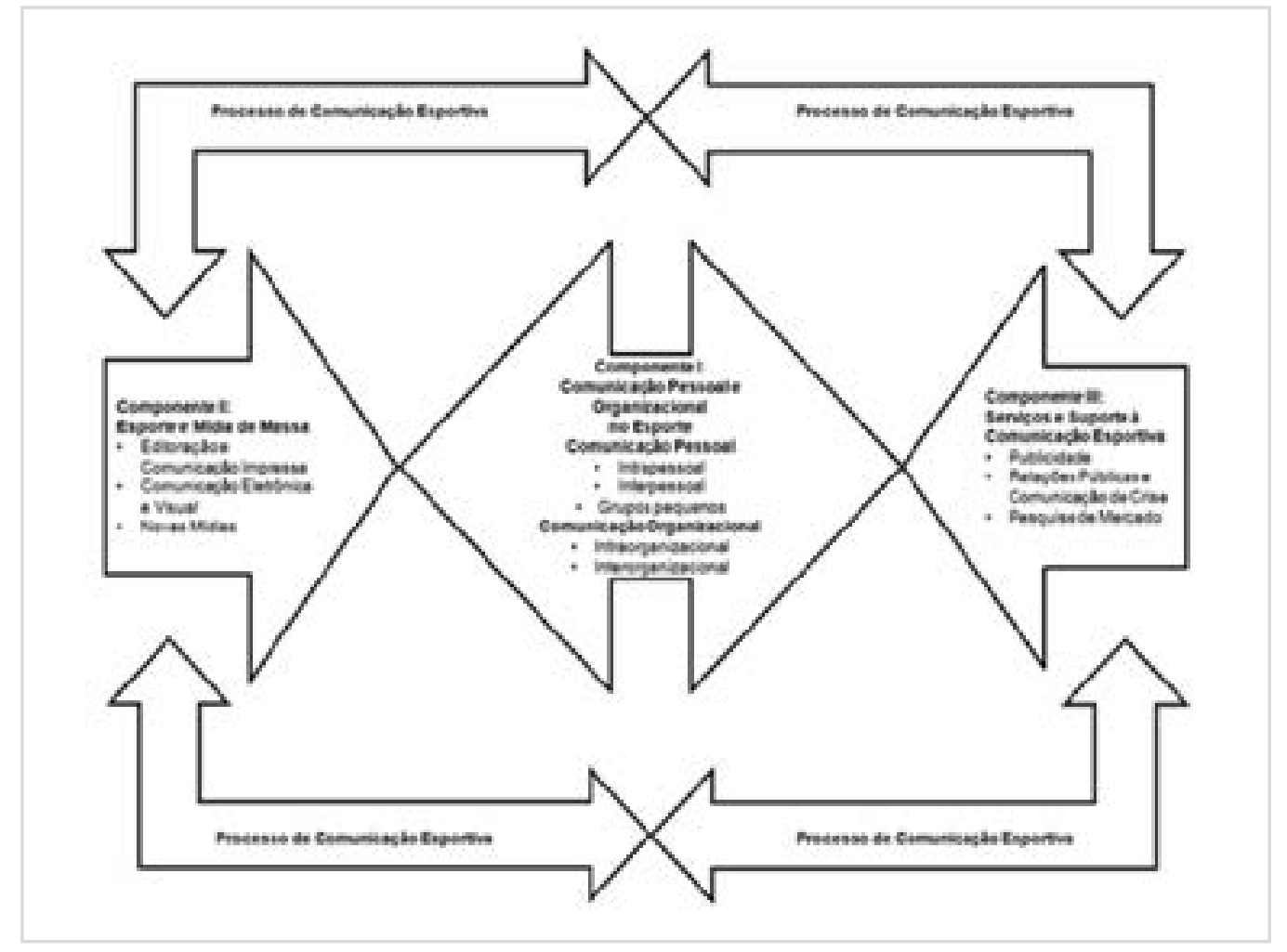

Fonte: Adaptado pelos autores de Pedersen, Miloch e Pamela, 2007, p. 85.

0 modelo proposto pelos pesquisadores norte-americanos envolve a organização esportiva em seu relacionamento com o mercado, com seus torcedores e fãs, com seus colaboradores e com diversos outros grupos de interesses que orbitam em tono das organizações esportivas. Trata-se de um modelo para a gestão estratégica da comunicação específica para as organizações esportivas. Os autores dividem a comunicação nas entidades que trabalham com 0 esporte, conforme Figura 2, em três componentes: comunicação pessoal e organizacional no esporte; esporte e mídia de massa; e serviços e suporte à comunicação esportiva.

As características do produto esportivo fizeram crescer a importância da comunicação integrada. Com o apoio da mídia, um processo de gestão bem estruturado, que implante, desenvolva, comunique e deixe transparecer os valores da agremiação para todos os stakeholders de uma entidade esportiva, certamente trará benefícios econômicos, financeiros e esportivos para o clube e a federação ou a confederação que a implantar.

0 desenvolvimento de uma identidade organizacional, por exemplo, integra os agentes internos da organização esportiva com seu posicionamento de mercado. A forma de agir, as atitudes dos atletas, seu comportamento dentro e fora das praças esportivas, a forma de praticar o esporte, o relacionamento com a comunidade, as postagens de clubes e atletas nas redes sociais, todos esses elementos comunicacionais devem estar integrados e colaboram, tanto para a conquista de títulos, a performance esportiva, como também para o correto e desejado posicionamento no mercado de consumo de bens e serviços esportivos, sua rentabilidade econômica e financeira. Todos esses elementos devem estar absolutamente integrados e equilibrados.

Assim, a comunicação integrada encontra, no esporte contemporâneo, território profícuo para desempenhar seu papel com plenitude. 0 caráter intangível do produto esportivo, quando bem trabalhado pelos profissionais de comunicação, permite 
a construção de forte apelo institucional para a consolidação de uma cultura sólida para entidades esportivas. 0 marketing passa, então, a funcionar como ferramenta de apoio de um processo maior, o da própria comunicação integrada.

No ECA club management guide (ECA, 2015), os clubes de futebol da Europa assumiram, como premissa básica, o modelo apresentado na Figura 3 como princípio para o desenvolvimento de suas estratégias individuais.

Figura 3 - Modelo de gestão dos clubes europeus.

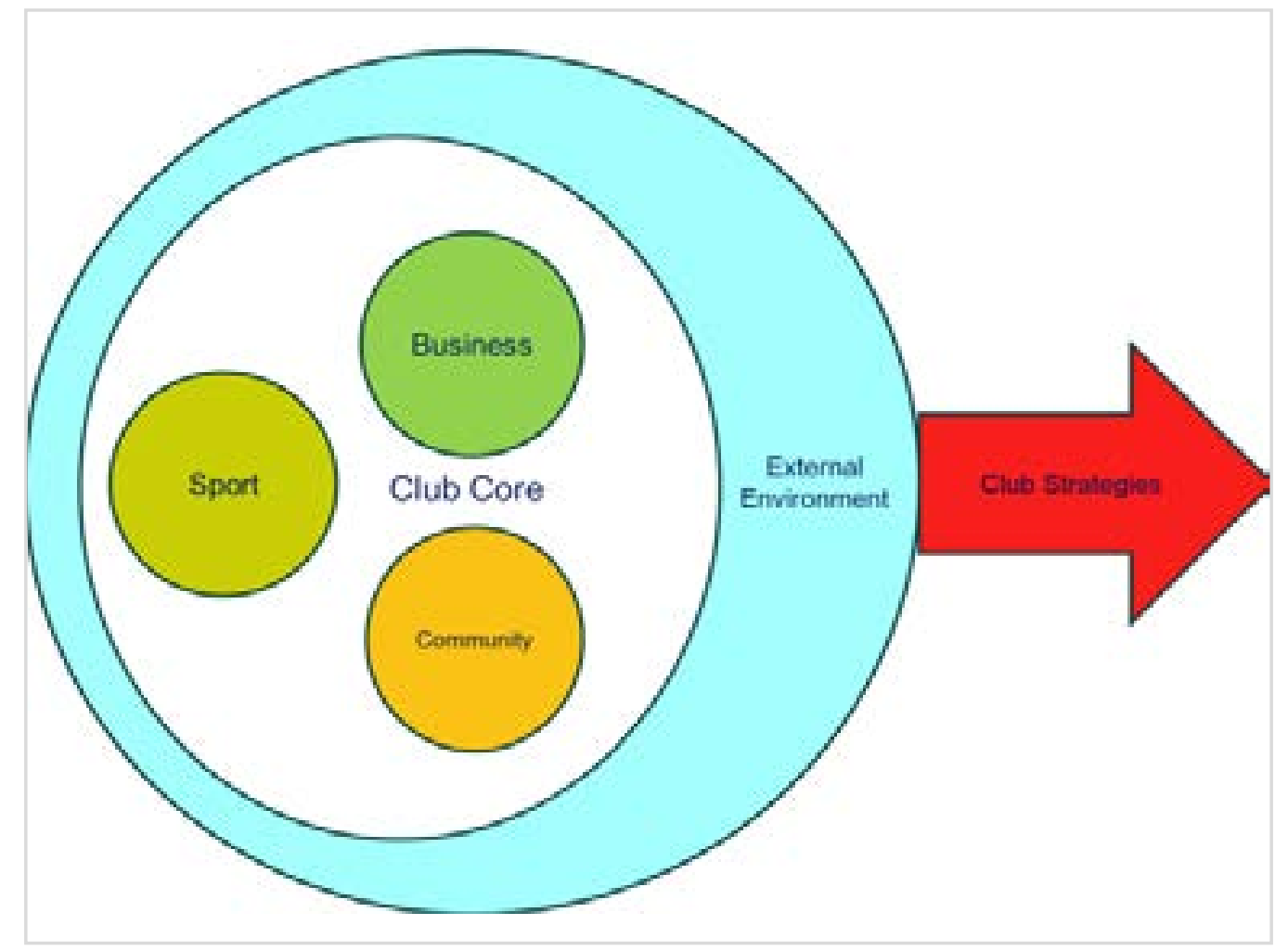

Fonte: Adaptado pelos autores de ECA, 2015, p. 4.

Os clubes europeus dividem seu núcleo central (club core) de atividades em três grandes grupos: Esporte (Sport), Negócios (Business) e Comunidade (Community). As estratégias de atuação das agremiações europeias (club strategies) devem combinar ações voltadas para o êxito no campo esportivo, com a conquista de boas performances nas competições que disputam; a obtenção de resultados econômicos e financeiros, com excelente posicionamento de mercado e valorização de suas marcas; e, finalmente, a construção de um relacionamento sólido com a comunidade e/ou com os diversos agentes com os quais as organizações se relacionam. A comunicação assume, assim, importante papel na construção dessas pontes de relacionamento com a comunidade e a sociedade como um todo.

Interessante observar que, ao lado das vitórias e da lucratividade de seus negócios, as agremiações esportivas da Europa reconhecem e valorizam a importância do relacionamento com a comunidade como um dos três principais vetores estratégicos de suas atividades. Cresce, nesse cenário, a importância da comunicação com a comunidade no desenvolvimento de uma identidade institucional e na consolidação de uma marca forte, firmemente alicerçada em valores e princípios próprios da organização.

Em seu documento, o ECA club management guide (ECA, 2015) divide o relacionamento com a comunidade em três níveis: de curto prazo, com ações pontuais e planejadas que contribuam na construção de um relacionamento sólido e de aproximação com sua comunidade de torcedores, local ou globalmente (com o auxílio das redes sociais); de médio prazo, com o desenvolvimento da construção e comunicação dos valores de identidade institucional; e de longo prazo, com a elaboração de um planejamento estratégico de políticas sociais que aproximem os clubes dos seus mais diversos públicos. 


\section{ANO 13 • NÚMERO 24 • 1은. 2016 - ORGANICOM COMUNICAÇÃO COMUNITÁRIA E RESPONSABILIDADE SOCIAL EM CLUBES DE FUTEBOL DO BRASIL E DA EUROPA: MUITO ALÉM DO "SÓCIO-TORCEDOR"}

As agremiações europeias enxergam a comunidade e a responsabilidade social como elementos estratégicos para criar forte vínculo de identidade com sua comunidade de torcedores (ECA, 2015, p. 195).

As ações de responsabilidade social corporativa promovem uma integração do clube com seus adeptos, criando uma relação não necessariamente motivada por resultados esportivos, mas sim pela filosofia de atuação e pelos valores da agremiação. Estrategicamente a responsabilidade social corporativa permite ao clube o acesso a financiamento público para a promoção do bem-estar social e possibilita aos seus patrocinadores a ação conjunta de atividades estrategicamente planejadas que contribuam para a construção de uma imagem positiva da relação clube/investidor (ECA, 2015, p. 195).

No contexto desportivo, a "imersão"' nas relações sociais pode ser facilmente encontrada no conceito tradicional de clubes ("sociedades"'), por exemplo, na Inglaterra e na Alemanha, que estão fortemente interligados com outras redes sociais. Assim, a ideia de partes interessadas não é nova para o futebol. No entanto, algumas noções importantes são novas para uma moderna gestão do futebol profissional: em primeiro lugar, o explícito reconhecimento das partes interessadas; em segundo, o grau de transparência exigido de conduta empresarial; terceiro, a interação com grupos que foram anteriormente "abandonados" pelos clubes, as minorias e os socialmente menos favorecidos; e, por fim, a necessidade de gerir estrategicamente as partes interessadas a fim de obter ou manter vantagens do jogo contra outras modalidades no mercado global indústria do esporte (Breitbarth; Harris, 2008, p. 183). ${ }^{2}$

Ao analisar a responsabilidade social corporativa no esporte, Paul Godfrey (2009) chamou atenção para a necessidade de as organizações esportivas serem tratadas, na sua essência, da mesma forma que as empresas que atuam em outros ramos de atividade no que concerne ao bom atendimento e relacionamento com a comunidade.

As quatro responsabilidades básicas dos gestores, previstas no modelo de Carroll (1979, apud Godfrey, 2009), para a administração de qualquer negócio, foram lembradas pelo pesquisador norte-americano: as responsabilidades de referência (do local onde atuam), de rentabilidade, econômicas e jurídicas.

0 modelo de Carroll se mostrou útil em dois aspectos. Em primeiro lugar, as quatro responsabilidades criam uma análise significativa e útil das responsabilidades não econômicas de uma empresa para diferenciar entre obrigatórios (responsabilidades legais), contextuais (normas éticas) e as dimensões opcionais (discricionárias) (Godfrey, 2009, p. 704). ${ }^{3}$

Além dos aspectos relacionados à gestão, Eduardo Yamamoto (2014) frisa que, com o desenvolvimento das mídias sociais nos últimos anos, o conceito de comunidade tem se modificado. Essas transformações sociais afetaram sobremaneira a comunicação comunitária dentro das organizações.

No caso da comunicação comunitária, é unânime o uso do termo para se referir ao conjunto de elementos presentes nos espaços marginalizados da cidade. Assim, seu qualificativo comunicacional estende-se aos aparelhos técnicos de comunicação utilizados por essas pessoas para dar visibilidade às suas demandas: precária situação material, reivindicação de assistência social básica (saúde, segurança, saneamento), divulgação dos serviços ou da arte que ali se produzem etc. Já no caso da cibercultura, a expressão da vontade comum comparece ao problema das solidariedades digitais, interessadas tanto na economia colaborativa entre os diferentes grupos, quanto na afirmação identitária e nas trocas e negociações intersubjetivas (Yamamoto, 2014, p. 439-440).

Com base em tudo o que foi exposto acima, clubes e entidades esportivas não podem, em suas atividades estratégicas, menosprezar ações de responsabilidade social corporativa e de comunicação com a comunidade. Tais ações fazem parte da essência dessas entidades e as auxiliam, de forma sólida, na construção de elementos identitários coesos na relação com seus mais diversos stakeholders. As entidades esportivas da Europa parecem, em comparação com as organizações brasileiras, já ter percebido isso há algum tempo, obtendo, com isso, vantagem competitiva tanto esportiva como mercadológica. 


\section{ANO 13 • NÚMERO 24 • 1은. 2016 - ORGANICOM COMUNICAÇÃO COMUNITÁRIA E RESPONSABILIDADE SOCIAL EM CLUBES DE FUTEBOL DO BRASIL E DA EUROPA: MUITO ALÉM DO "SÓCIO-TORCEDOR"}

\section{METODOLOGIA DE PESQUISA}

Conforme já mencionado, no início de 2015 a The European Club Association (ECA) divulgou o ECA club management guide. A publicação procurou analisar a gestão de aproximadamente 220 clubes de 53 países europeus, estabelecendo padrões de atuação para a gestão das entidades esportivas do Velho Continente. 0 material avaliou, também, as políticas e estratégias dos principais clubes europeus, dividindo as atividades organizacionais das entidades estudadas em três grandes grupos: performance esportiva; negócios; e atuação junto à comunidade e responsabilidade social.

Em função do destaque dado à comunidade, a intenção do presente artigo foi analisar, de forma comparativa, com base naquilo que é comunicado pelos seus portais oficiais na internet, a comunicação com a comunidade estabelecida pelos oito principais clubes europeus e brasileiros. Com isso, foram levantadas as políticas de gestão voltadas para a comunicação comunitária e a responsabilidade social das mais importantes agremiações europeias e brasileiras.

Antes da efetiva análise comparativa da comunicação com a comunidade dos clubes pertencentes aos dois cenários - 0 europeu e o brasileiro -, um extenso trabalho de revisão bibliográfica e de análise documental foi realizado por nós. Estudaram-se, nessa primeira etapa da pesquisa, o material elaborado pela The European Club Association e os documentos sobre comunicação comunitária e responsabilidade social divulgados em seus sitespelos dezesseis clubes (oito europeus e oito brasileiros) analisados.

Posteriormente, na fase principal da pesquisa, através da observação direta dos portais dos clubes selecionados, foram avaliados os aspectos comunicacionais de cada uma das entidades observadas no que diz respeito às suas ações junto à comunidade e de responsabilidade social. Com isso, para a análise dos resultados obtidos, foi possível a estruturação de um painel de casos múltiplos, construído com base nas dezesseis agremiações estudadas.

Para a realização dessa investigação, com o atingimento dos objetivos propostos, realizamos a análise documental dos diversos veículos impressos de comunicação organizacional produzidos pelas dezesseis equipes estudadas nessa pesquisa e, também, documentos disponibilizados por essas agremiações, como estatutos, relatórios financeiros, relatórios de responsabilidade social, relatórios gerenciais e de planejamento estratégico, entre outros.

A análise de documentos para estudos de caso, segundo Robert K. Yin (2010), corrobora e valoriza as evidências oriundas de outras fontes. 0 autor sugere que a análise de documentos apresenta, em um processo de pesquisa, como pontos fortes, ser estável, discreta, exata e oferece ampla cobertura de eventos ocorridos no interior da organização.

Também, e como fonte principal de informação, trabalhamos com a observação direta e a análise minuciosa e detalhada dos portais oficiais gerenciados pelas dezesseis agremiações que foram objetos de estudo deste projeto de pesquisa. Entendemos, no espectro dessa investigação, que os sites oficiais dos clubes de futebol evidenciam, ou pelo menos deveriam evidenciar, as estratégias de comunicação colocadas em prática por cada uma dessas organizações objetos do nosso estudo. A observação dos portais dos principais clubes do Brasil e da Europa foi realizada no período de 01 de maio a 31 de julho de 2015.

De acordo com Yin (2010), as provas observacionais são úteis para fornecer informações sobre o objeto de estudo. Para o autor, a observação direta oferece, ainda, ao pesquisador, o acesso à realidade e ao contexto do fenômeno, no caso aqui a comunicação comunitária, observado, uma vez que refletem a organização em tempo real e o ambiente em que os fenômenos a ser observados acontecem. 


\section{ANO 13 • NÚMERO 24 • 1은. 2016 - ORGANICOM COMUNICAÇÃO COMUNITÁRIA E RESPONSABILIDADE SOCIAL EM CLUBES DE FUTEBOL DO BRASIL E DA EUROPA: MUITO ALÉM DO "SÓCIO-TORCEDOR"}

Para a escolha das oito agremiações europeias que foram objetos deste estudo, foi necessário definir um critério claro e objetivo, que refletisse os resultados de uma adequada gestão da comunicação integrada nas instituições elegidas. Sete agremiações foram escolhidas com base no Brand finance football 50 (Brand, 2015), relatório que elenca as cinquenta maiores equipes do futebol mundial, por valor de suas marcas.

Para a consultoria europeia, o conceito de marca utilizado para a elaboração do relatório mencionado, representa, em sentido amplo, o foco de todas as expectativas e opiniões sustentadas pelos fãs, jogadores, funcionários e por outras partes interessadas sobre um clube de futebol (Brand, 2015).

Porém, ao entender o conceito de marca como ativo de negócios que podem ser comprados, vendidos e licenciados, o relatório preferiu definir marca como "um ativo intangível relacionado ao marketing, incluindo nomes, termos, sinais, símbolos, logos e desenhos ou uma combinação destes" (Brand, 2015, p. 89). Algo que identifique bens, serviços ou entidades, ou uma combinação destas, com a criação de imagens e associações distintivas nas mentes das partes interessadas, gerando assim economia de benefícios/valor. Assim, a força de uma marca no futebol, para o relatório da consultoria britânica, será influenciada direta e facilmente por suas estratégias de comercialização e gestão, bem como pelo seu sucesso em campo (Brand, 2015).

Entendemos, em razão do exposto acima, para nossa escolha, que as estratégias de comunicação organizacional colaboram de forma pungente para a valorização das marcas das entidades esportivas no mercado mundial do esporte. As equipes elegidas foram estas: Manchester United (Inglaterra), Bayern de Munique (Alemanha), Real Madrid (Espanha), Manchester City (Inglaterra), Chelsea (Inglaterra), FC Barcelona (Espanha) e Arsenal (Inglaterra). A oitava agremiação escolhida, o Benfica (Portugal), fez parte desse estudo em razão de ser, em todas as pesquisas realizadas sobre o tema, o clube do mundo com o maior número de associados (Exame.com, 2015). Em razão disso, julgamos interessante a inclusão do clube português como objeto do nosso estudo.

Já os oito clubes de futebol do Brasil foram escolhidos, para o escopo desta pesquisa, com base no estudo da BDO Brasil (BDO, 2015), publicado no início de 2015, com as trinta marcas mais valiosas entre as agremiações esportivas do país. As entidades por nós selecionadas foram as oito com marcas mais valiosas: Flamengo (RJ), Corinthians (SP), São Paulo (SP), Palmeiras (SP), Grêmio (RS), Internacional (RS), Cruzeiro (MG) e Santos (SP).

Em seu relatório, a consultoria brasileira inclui 21 diferentes variáveis para estabelecer o valor de marca dos clubes do país. Entre essas variáveis encontramos dados financeiros históricos dos clubes, informações publicadas em pesquisas com os torcedores, dados de marketing esportivo, hábitos de consumo dos torcedores e dados sociais e econômicos do mercado em que atuam as agremiações analisadas (BDO, 2015).

As receitas diretamente relacionadas ao cálculo do valor da marca, no documento da BDO Brasil (2015), foram consolidadas em quatro principais receitas: marketing, estádio, sócios e mídia. Assim, além da força da torcida, o valor da marca considera outras variáveis, como as receitas derivadas da sua marca, os hábitos do torcedor e características do mercado local, fazendo com que o crescimento ou a queda do valor da marca não seja atribuído a um aspecto isolado.

Ao contrário do relatório da Brand Finance, a metodologia do estudo da BDO Brasil não considera o valor dos ativos registrados nas demonstrações contábeis dos clubes e sim as receitas derivadas por esses ativos. Assim, para um clube crescer no valor e sua marca, sempre é considerado o esforço de maximizar suas receitas e não o valor contábil do ativo em si (BD0, 2015). 
Apesar das diferenças conceituais entre os dois instrumentos - o europeu e o brasileiro -, entendemos que os relatórios representam, com consistência, as principais equipes, em valor de marca, dos dois mercados que comparamos.

Mediante um protocolo de observação, previamente elaborado, realizamos em cada um dos dezesseis portais das agremiações já mencionadas, durante o período já relatado, a coleta dos dados necessários para a pesquisa. Foram destacadas informações referentes aos processos de gestão da comunicação com a comunidade e de divulgação de ações de responsabilidade social corporativa das entidades selecionadas para este estudo.

Yin (2010) aponta a elaboração de protocolo de estudos de caso como forma de preparação para a coleta e o levantamento de dados. 0 autor afirma, ainda, que o protocolo de estudo de caso é especialmente essencial para a utilização, como é 0 caso de nossa pesquisa, em projeto de casos múltiplos e como tática para aumentar a confiabilidade da pesquisa.

Após a coleta de dados orientada por um protocolo de pesquisa, com a observação direta dos portais das dezesseis agremiações esportivas selecionadas, partimos para a terceira etapa do projeto de investigação: a análise comparativa dos dados obtidos entre as agremiações europeias e brasileiras.

A etapa final do foi a avaliação, a análise e o desenvolvimento da comparação entre Europa e Brasil dos dados obtidos no processo de coleta de dados. Foi nossa intenção avaliar, através do método de análise cruzada dos casos das dezesseis equipes pesquisadas, as semelhanças e diferenças no atual estágio de desenvolvimento de filosofias de comunicação comunitária e responsabilidade social nas principais esquipes de futebol do Velho Continente e do nosso país.

Para a análise dos dados coletados, os casos estudados foram apresentados no formato de painel, baseado no protocolo de estudo previamente elaborado ao processo de levantamento das informações.

0 painel com os dados obtidos oferece um resumo das evidências coletadas. Para Paulo A. Cauchick Miguel (2012, p. 142), "se múltiplos casos são empregados, deve-se construir um painel para cada caso para, em seguida, fazer uma análise cruzada dos dados, identificando convergências e divergências entre as fontes de evidências". 0 autor completa que "estes painéis permitem identificar mais facilmente padrões e mostrar o relacionamento entre as variáveis de pesquisa" (Miguel, 2012, p. 142).

A partir da análise e interpretação cruzada dos dados obtidos nos dezesseis casos analisados, foi possível avaliar os modelos de implantação da filosofia de comunicação comunitária e responsabilidade social corporativa nas principais organizações esportivas da Europa e compará-los, de forma consistente, àquilo que ocorre nas mais importantes agremiações de futebol do Brasil. Era esse o objeto central deste estudo.

\section{RESULTADOS E DISCUSSÕES}

Como já mencionado, as agremiações europeias colocam o relacionamento com a comunidade como um dos elementos fundamentais, ao lado dos negócios (mercado) e do sucesso esportivo, elementos do tripé que deve nortear as estratégias dos clubes e entidades que atuam no campo esportivo.

No Brasil, como demonstram os dados obtidos, o relacionamento com a comunidade ocupa lugar secundário dentro das escassas estratégias planejadas pelos dirigentes dos clubes esportivos que atuam no país. Essa discrepância na gestão 
da comunicação estratégica institucional dos clubes esportivos existente entre Europa e Brasil contribui sobremaneira para a dificuldade experimentada atualmente pelas agremiações nacionais para a construção de vínculos identitários fortes e consolidados com sua comunidade de fãs, torcedores e consumidores. Os resultados obtidos para a comunicação comunitária e a responsabilidade social, apresentados de forma resumida na Tabela 1, ilustram bem esse fenômeno.

É no tratamento dado à comunicação comunitária e à responsabilidade social que as diferenças entre as agremiações europeias e as brasileiras mais se evidenciam. 0 relacionamento com a comunidade ainda não atingiu, nas agremiações esportivas brasileiras, a maturidade que é possível observar nos clubes europeus. Com exceção do Bayern de Munique, da Alemanha, todas as demais agremiações do Velho Continente estruturaram fundações para gerenciar seus projetos sociais em todo o mundo e administrar, em bases sólidas, o relacionamento com a comunidade.

Tabela 1 - Comunicação comunitária e responsabilidade social corporativa

\begin{tabular}{|c|c|c|}
\hline & Clubes europeus & Clubes brasileiros \\
\hline $\begin{array}{l}\text { Espaço para } \\
\text { relacionamento com } \\
\text { investidores (sócios) }\end{array}$ & $\begin{array}{l}\text { Todos os clubes pesquisados possuem } \\
\text { amplo espaço estruturado e com } \\
\text { variadas informações para sócios, } \\
\text { sócios-torcedores e investidores. }\end{array}$ & $\begin{array}{l}\text { Todos os clubes pesquisados possuem } \\
\text { amplo espaço estruturado e com } \\
\text { variadas informações para sócios, } \\
\text { sócios-torcedores e investidores. }\end{array}$ \\
\hline $\begin{array}{l}\text { Material para } \\
\text { orientação de } \\
\text { investidores (sócios) }\end{array}$ & $\begin{array}{l}\text { Todos os oito clubes pesquisados possuem } \\
\text { informações amplas e variadas sobre seu } \\
\text { processo de governança corporativa. }\end{array}$ & $\begin{array}{l}\text { Todos os oito clubes pesquisados } \\
\text { possuem ações para orientação dos } \\
\text { associados/investidores basicamente } \\
\text { através de portais exclusivos, centrais } \\
\text { de atendimento e/ou ouvidoria. }\end{array}$ \\
\hline $\begin{array}{l}\text { Espaço para } \\
\text { relacionamento } \\
\text { com a comunidade } \\
\text { (sociedade) }\end{array}$ & $\begin{array}{l}\text { Todas as oito equipes pesquisadas } \\
\text { apresentam espaço estruturado, em } \\
\text { seus portais, destinados a retratar o } \\
\text { relacionamento com a comunidade } \\
\text { (local, nacional e mundial). }\end{array}$ & $\begin{array}{l}\text { Das oito equipes pesquisadas, apenas } \\
\text { três (Santos, Internacional e Grêmio) } \\
\text { possuem informações claras e objetivas } \\
\text { sobre seu relacionamento com a } \\
\text { comunidade. Corinthians e Flamengo } \\
\text { divulgam, de forma impressa, relatórios } \\
\text { de responsabilidade social. }\end{array}$ \\
\hline $\begin{array}{l}\text { Ações para } \\
\text { relacionamento } \\
\text { com a comunidade } \\
\text { (sociedade) }\end{array}$ & $\begin{array}{l}\text { Todas as oito equipes pesquisadas } \\
\text { apresentam vasto rol de programas } \\
\text { e ações sociais para relacionamento } \\
\text { de suas comunidades locais } \\
\text { (preferencialmente), nacional e mundial. }\end{array}$ & $\begin{array}{c}\text { Das oito equipes pesquisadas, duas } \\
\text { (Palmeiras e Cruzeiro), não apresentam } \\
\text { nenhuma ação de relacionamento com a } \\
\text { comunidade. As outras seis agremiações } \\
\text { possuem ações de relacionamento } \\
\text { com a comunidade apenas em nível } \\
\text { local, no máximo estadual. }\end{array}$ \\
\hline
\end{tabular}




\begin{tabular}{|c|c|c|}
\hline & Clubes europeus & Clubes brasileiros \\
\hline $\begin{array}{l}\text { Relatórios de } \\
\text { responsabilidade social }\end{array}$ & $\begin{array}{l}\text { Das agremiações pesquisadas, somente } \\
\text { duas (Manchester United e Bayern de } \\
\text { Munique) não apresentam relatórios } \\
\text { e/ou informações para download de } \\
\text { suas atividades comunitárias. }\end{array}$ & $\begin{array}{l}\text { Das agremiações pesquisadas, somente } \\
\text { duas (Corinthians e Flamengo) } \\
\text { apresentam relatórios e/ou informações } \\
\text { para download de suas atividades. }\end{array}$ \\
\hline $\begin{array}{l}\text { Atletas participam } \\
\text { de ações sociais }\end{array}$ & $\begin{array}{l}\text { Dos oito clubes pesquisados, somente } \\
\text { um (Bayern de Munique) não apresenta } \\
\text { informações sobre a participação de } \\
\text { seus atletas em suas ações sociais. Em } \\
\text { todos os outros, os atletas e treinadores } \\
\text { participam ativamente desse tipo de ação. }\end{array}$ & $\begin{array}{l}\text { Dos oito clubes pesquisados, quatro } \\
\text { (Corinthians, São Paulo, Palmeiras e } \\
\text { Cruzeiro) não apresentam informações } \\
\text { sobre a participação de seus atletas em } \\
\text { suas ações sociais. Em todos os outros, } \\
\text { os atletas e treinadores participam } \\
\text { ativamente desse tipo de ação. }\end{array}$ \\
\hline Fundação estruturada & $\begin{array}{l}\text { Das oito equipes pesquisadas, somente uma } \\
\text { (Bayern de Munique) não apresenta uma } \\
\text { fundação estruturada, com pessoal próprio, } \\
\text { destinada a investir no relacionamento com } \\
\text { a comunidade (local, nacional e mundial). }\end{array}$ & $\begin{array}{l}\text { Das oito equipes pesquisadas, somente } \\
\text { uma (Internacional) apresenta uma } \\
\text { fundação estruturada e outra (Grêmio) } \\
\text { conta com um instituto, com pessoal } \\
\text { próprio, destinado a investir no } \\
\text { relacionamento com a comunidade } \\
\text { (local). Outra (Corinthians) conta com } \\
\text { departamento próprio para essa finalidade. }\end{array}$ \\
\hline $\begin{array}{l}\text { Número de projetos } \\
\text { sociais e pessoas } \\
\text { atendidas }\end{array}$ & $\begin{array}{l}\text { Das agremiações pesquisadas, somente } \\
\text { duas (Manchester United e Bayern de } \\
\text { Munique) não apresentam informações } \\
\text { sobre o número de projetos desenvolvidos } \\
\text { e de indivíduos atendidos pelas fundações. }\end{array}$ & $\begin{array}{l}\text { Das agremiações pesquisadas, somente } \\
\text { duas (Corinthians e Internacional) } \\
\text { apresentam informações sobre o } \\
\text { número de projetos desenvolvidos e de } \\
\text { indivíduos atendidos pelos clubes. }\end{array}$ \\
\hline $\begin{array}{l}\text { Planejamento } \\
\text { estratégico das } \\
\text { ações sociais }\end{array}$ & $\begin{array}{l}\text { Dos clubes pesquisados, somente o Bayern } \\
\text { de Munique não apresenta evidências } \\
\text { da existência de um planejamento } \\
\text { estratégico para suas ações sociais. }\end{array}$ & $\begin{array}{l}\text { Dos clubes pesquisados, somente o Grêmio } \\
\text { apresenta planejamento estratégico } \\
\text { para suas ações sociais. Outros quatro } \\
\text { clubes (Corinthians, Santos, Flamengo } \\
\text { e Internacional) apresentam evidências } \\
\text { da existência de planeajamento } \\
\text { estratégico para sua atuação social. }\end{array}$ \\
\hline
\end{tabular}

Fonte: Elaborado pelos autores com base nas informações fornecidas nos portais oficiais dos dezesseis clubes pesquisados.

As fundações dos clubes europeus, com gestão e organograma próprios, apresentam resultados altamente positivos no atendimento de indivíduos em situação de risco. Também fazem parte, de forma evidente, do planejamento estratégico dos clubes da Europa. Essa relação contribui, assim, para que a imagem dessas agremiações se fortaleça junto aos seus mais diversos grupos de interesses. Além disso, asseguram aos clubes a credibilidade que, ao final da cadeia estratégia, representa 
um aporte maior de torcedores e de empresas interessadas em investir nessas agremiações e no universo do futebol no Velho Continente. Essa credibilidade traz um imenso retorno de imagem por parte de investidores e patrocinadores.

No Brasil, apenas o Sport Club Internacional de Porto Alegre (RS), conta com uma fundação legalmente constituída e com equipe de gestão própria. Porém, a atuação da fundação do clube gaúcho ainda é bastante tímida e limitada em comparação com aquilo que ocorre nas entidades europeias. 0 Grêmio é outra equipe brasileira que conta com uma entidade específica para o gerenciamento de projetos sociais e de relacionamento da agremiação com a comunidade. Também com equipe de gestão própria, esse clube gaúcho conta com um instituto, que desempenha papel interessante junto à comunidade carente da capital do Rio Grande do Sul.

O Sport Club Corinthians Paulista, da cidade de São Paulo, foi o pioneiro, entre as equipes brasileiras, na elaboração de seu relatório de responsabilidade social. Ele divulgou seu primeiro relatório dedicado às suas ações na área em 2008. Porém, em uma análise mais detalhada, é possível verificar que os relatórios do Corinthians se assemelham muito mais a peças de marketing do que a uma comunicação concreta e objetiva de suas ações de responsabilidade social.

Obviamente, todo o esforço das equipes europeias leva a um melhor gerenciamento de sua imagem junto aos seus stakeholders. A identidade das agremiações é trabalhada em torno de seus elementos estratégicos: missão, visão, princípios, valores e filosofia de atuação. Tudo muito bem comunicado através dos seus portais oficiais e de ações estrategicamente planejadas.

Enquanto isso, os clubes brasileiros apresentam, como elementos identitátios, em seus portais, o hino oficial, o mascote, o símbolo do clube, suas cores e sua bandeira oficial. A ausência de elementos estratégicos que reflitam a identidade das agremiações dificulta a construção de uma comunicação mais eficiente. Os clubes brasileiros, em vez de pensarem de forma estratégica suas identidades, demonstram preocupação com a gestão de suas marcas.

Por fim, outra diferença importante e que merece destaque é o tratamento dado aos associados e/ou investidores.

No Brasil, atualmente, os clubes passaram a dedicar amplo espaço para os sócios-torcedores. Os sócios-torcedores são indivíduos que pagam, mensalmente, um valor para receber das agremiações, em troca, benefícios como descontos em produtos, privilégios para aquisição de ingressos, dentre outros. Os diversos programas de sócios-torcedores dos clubes brasileiros representam, em sua essência, ações de marketing para que as agremiações nacionais incrementem suas receitas.

Já os associados, indivíduos que constituem o quadro associativo social dos clubes brasileiros, também contam com espaço privilegiado nos portais das organizações esportivas brasileiras. No entanto, como foi possível observar na maioria dos sites das agremiações nacionais, o maior destaque do processo de comunicação institucional dos clubes do país é dado ao relacionamento com o sócio-torcedor, personagem importante para a melhoria da arrecadação dos clubes no Brasil.

Os clubes europeus também dedicam espaço amplo para seus torcedores filiados, os chamados memberships. Porém, também oferecem amplas informações, em especial no caso inglês e no do Benfica (Portugal), sobre possibilidades de investimentos e/ou aportes de capital nas respectivas agremiações.

$\mathrm{Na}$ Espanha, onde o FC Barcelona e o Real Madrid são clubes associativos em modelo semelhante ao brasileiro, os associados recebem tratamento privilegiado nos portais das duas agremiações. As entidades espanholas fazem questão absoluta, em suas 
páginas oficiais, de manter uma relação direta de transparência com seus associados. Há documentos de prestação de contas dos dirigentes, escolhidos pelos associados para dirigir o clube, à disposição para download nos portais das duas agremiações.

Há, neste caso, uma diferença grande entre os objetivos estratégicos das equipes europeias e mercadológicos das agremiações brasileiras. Obviamente, esse fato se reflete nas estratégias de comunicação dos dois grupos de entidades esportivas.

Para os clubes brasileiros, a comunicação comunitária estratégica se reveste, assim, de forte cunho mercadológico. Já para as agremiações da Europa, a construção de uma imagem sólida, alicerçada em uma comunicação comunitária de qualidade, passa a ser um fator crítico de sucesso no competitivo mercado do entretenimento global.

As entidades esportivas europeias entendem, de forma acertada e como já demonstrou Kunsch (2003), que sua imagem, estrategicamente planejada, se refletirá, de forma clara e concreta, em um excelente posicionamento de mercado. 0 desenvolvimento correto e adequado do gerenciamento das comunicações interna e externa, dentro do conceito de comunicação integrada (Kunsch, 2003), traz excelentes reflexos nos resultados econômico e financeiro das organizações esportivas da Europa.

Os clubes brasileiros enxergam, desta forma, a comunicação comunitária como algo que se confunde com sua comunicação mercadológica, não explorando, em sua plenitude, as amplas possibilidades oferecidas por uma estratégia correta de comunicação integrada (Kunsch, 2003).

Já as agremiações europeias utilizam de forma estratégica a comunicação comunitária para a construção de uma imagem sólida e consistente junto a seus principais stakeholders. Adotam, assim, um modelo de comunicação estratégica para 0 esporte semelhante ao modelo teórico proposto pelos pesquisadores norte-americanos Pedersen, Miloch e Laucella (2007).

\section{CONSIDERAÇÕES FINAIS}

As principais equipes de futebol da Europa, como demonstrado, já perceberam a importâncias das estratégias de comunicação com a comunidade e de responsabilidade social para a consolidação de identidades sólidas e, como consequência, valorização de suas marcas no mercado internacional do esporte.

As ações de comunicação comunitária fornecem às marcas europeias o poder de influenciar consumidores, parceiros, colaboradores e de interferir na vida da comunidade. Com isso, mobilizam o interesse dos investidores, transformando o desempenho da organização e seu resultado financeiro.

0 entendimento de que uma identidade forte é, hoje, ativo financeiro de uma organização dá ao esporte uma importância estratégica. Atletas, clubes e modalidades esportivas passam a contribuir, assim, de forma cada vez mais preponderante, para o sucesso de uma empresa. 0 papel da comunicação com a comunidade cresce em importância dentro desse universo. 0 planejamento da comunicação com os stakeholders passa a ser uma das principais estratégias para os agentes esportivos e os gestores do esporte conquistarem resultados econômico, político e esportivo.

Todo esse cenário já foi entendido pelas principais agremiações de futebol da Europa. No Brasil, em contrapartida, os clubes mais importantes do país aparentam ainda não ter compreendido esse processo. As agremiações nacionais ainda apostam 
em estratégias para a comunidade mais vinculadas ao marketing do que à comunicação. Várias ações de relacionamento com atletas, como as escolinhas de futebol, ou de comunicação com a comunidade, como os programas de sócio-torcedor, apresentam um caráter muito mais mercadológico do que de construção de relacionamento com seus grupos de interesses.

Prevalece, nos processos de comunicação comunitária propostos pelos clubes europeus em seus portais, uma preocupação com a construção de uma imagem sólida, mediante o estabelecimento de relacionamentos consistentes com seus principais stakeholders, especialmente seus associados, torcedores, consumidores, investidores, órgãos de imprensa, comunidade e consumidores. Esse processo, construído em torno da comunicação com a comunidade, como na Europa, leva ao fortalecimento e à valorização das marcas dos principais clubes europeus no mercado do futebol.

Já no Brasil, como observado, os processos de comunicação com a comunidade estão alicerçados em ações isoladas de marketing, sem um planejamento estratégicoadequado, que não refletem, em sua essência, a construção de relacionamentos concretos e duradouros com seus grupos de interesses. Tais ações evidenciam, assim, a falta de um planejamento estratégico que utilize, de forma correta e profissional, a comunicação como seu vetor estratégico mais importante.

Acreditamos que a metodologia utilizada para o presente estudo pode ser válida para análises futuras do tema em confederações, federações e outras entidades que apresentem o esporte como seu negócio principal. A metodologia permite, também, a comparação da comunicação comunitária dos clubes brasileiros com outros mercados do futebol mundial, como os Estados Unidos, a Argentina e qualquer outro país que apresente agremiações com portais oficiais na internet.

0 presente artigo apresenta, como limitação principal, o fato de ter trabalhado apenas com a análise da comunicação realizada pelas entidades esportivas no universo digital. Sabemos que, em muitas oportunidades, os portais oficiais das entidades esportivas se apresentam desatualizados, não refletindo o real estágio da comunicação das organizações. Além disso, o presente estudo também foi limitado pela dificuldade em conseguirmos entrevistar os principais gestores dos grandes clubes do país. Porém, apesar disso, acreditamos que, com as conclusões apresentadas, contribuímos para a melhoria da gestão da comunicação, de forma particular, e da gestão de entidades esportivas, de forma geral, no Brasil.

\section{REFERÊNCIAS}

BDO BRASIL. As 30 marcas mais valiosas do futebol brasileiro. São Paulo: BDO, 2015.

BRAND. Brand finance football 50. New York: Brand Finance, 2015.

BREITBARTH, Tim; HARRIS, Phil. The role of corporate social responsibility in the football business: towards the development of a conceptual model. European Sport Management Quarterly, v. 8, n. 2, p. 179-206, June 2008.

ECA.The European Clubs Association. (2015). ECA club management guide. Nyon: ECA, 2015.

EXAME.COM. Os 30 times com mais sócios-torcedores do mundo. 2015. Disponível em: <http://exame.abril.com.br/marketing/ album-de-fotos/os-30-times-com-mais-socios-torcedores-no-mundo>. Acesso em: 5 maio 2015.

GODFREY Paul C. Corporate social responsibility in sport: an overview and key issues. Journal of Sport Management, n. 23, p. 698-716, 2009. 
KUNSCH, Margarida M. Krohling. Planejamento de relações públicas na comunicação integrada. 4. ed. rev., ampl. e atual. São Paulo: Summus, 2003.

Comunicação organizacional: conceitos e dimensões dos estudos e das práticas. In: MARCHIORI, Marlene (org.). Faces da cultura e da comunicação organizacional. São Caetano do Sul, SP: Difusão, 2006. p. 167-190.

MIGUEL, Paulo A. Cauchick (org.). Metodologia de pesquisa em engenharia de produção e gestão de operações. 2. ed. São Paulo: Elsevier, 2012.

PEDERSEN, Paul; MILOCH, Kimberly S.; LAUCELLA, Pamela C. Strategic sport communication. Champaign: Human Kinetics, 2007.

YAMAMOTO, Eduardo Y. 0 conceito de comunidade na comunicação. Revista Famecos - Mídia, Cultura e Tecnologia, Porto Alegre, v. 21, n. 2, p. 438-458, maio-ago. 2014.

YIN, Robert K. Estudo de caso: planejamento e métodos. 4. ed. São Paulo: Bookman, 2010.

\section{Portais consultados}

Arsenal, http://www.arsenal.com

Barcelona, http://www.fcbarcelona.com

Bayern de Munique, http://www.fcbayern.de

Benfica, http://www.slbenfica.pt

Chelsea, http://www.chelseafc.com

Corinthians, http://www.corinthians.com.br

Cruzeiro, http://www.cruzeiro.com.br

Flamengo, http://www.flamengo.com.br

Grêmio, http://www.gremio.net

Internacional, http://www.internacional.com.br

Manchester City, http://www.manutd.com

Manchester City, http://www.mcfc.co.uk

Palmeiras, http://www.palmeiras.com.br

Real Madrid, http://www.realmadrid.com

São Paulo, http://www.saopaulofc.net

Santos, http://www.santosfc.com.br

Artigo recebido em 27.02.2016 e aprovado em 26.06.2016. 